2018-07

On the influence of reflection over a rhythmic swash zone on surf zone dynamics

\author{
Almar, $\mathrm{R}$ \\ http://hdl.handle.net/10026.1/11994
}

10.1007/s10236-018-1165-5

Ocean Dynamics

Springer Science and Business Media LLC

All content in PEARL is protected by copyright law. Author manuscripts are made available in accordance with publisher policies. Please cite only the published version using the details provided on the item record or document. In the absence of an open licence (e.g. Creative Commons), permissions for further reuse of content should be sought from the publisher or author. 


\title{
On the influence of reflection over a rhythmic swash zone on surf zone dynamics
}

\author{
Rafael Almar ${ }^{1}$, Alexandre Nicolae Lerma ${ }^{2}$, Bruno Castelle ${ }^{3}$ and Timothy Scott ${ }^{4}$
}

\begin{abstract}
The reflection of incident gravity waves over an irregular swash zone morphology and the resulting influence on surf zone dynamics remains mostly unexplored. The wave-phase resolving SWASH model is applied to investigate this feedback using realistic low-tide terraced beach morphology with well-developed beach cusps. The rhythmic reflection generates a standing wave that mimics a subharmonic edge wave, from the superimposition of incident and two-dimensional reflected waves. This mechanism is enhanced by shore-normal, narrow-banded waves in both direction and frequency. Our study suggests that wave reflection over steep beaches could be a mechanism for the development of rhythmic morphological features such as beach cusps and rip currents.
\end{abstract}

Keywords: Nearshore, beach cusps, reflection, edge wave, surf-swash interactions, low-tide terraced beach, SWASH model, Radon Transform, rip current

Highlights

- Reflection over a non-uniform shoreline generates an irregular wave pattern

- A single beach cusp is able to generate a standing wave, even at open beaches

- Mechanism more efficient for shore-normal narrow-banded incident waves

\footnotetext{
${ }^{1}$ IRD-LEGOS (Toulouse University /CNRS/CNES/IRD), Toulouse, France, ${ }^{2}$ BRGM (French Geological Survey), Risks and Prevention Division - Coastal Risks and Climate Change Unit, Orléans, France, ${ }^{3}$ CNRS, Université Bordeaux 1, UMR 5805-EPOC, 33405, Talence, France,

${ }^{4}$ University of Plymouth, Drake Circus, Plymouth, PL4 8AA, UK
} 


\section{Introduction}

Wave reflection up to $60-80 \%$ has been observed on very steep beaches in long period waves (Battjes, 1974; Elgar et al., 1994). This reflection was recently observed to have a profound influence on surf zone hydrodynamics, such as incident waves (Rocha et al., 2017) and return flow or undertow (Martins et al., 2017). While infragravity standing waves have attracted most of the interest on dissipative to intermediate barred beaches (Suhayda, 1974; Guza \& Bowen 1976; Mizuguchi, 1984; Contardo and Symonds, 2013; Inch et al., 2016), gravity standing waves on reflective beaches have received less attention (e.g. Guza and Chapman, 1979; Almar et al., 2016). Bryan and Bowen (1996) showed evidence of bar-trapped gravity edge waves, but they were not observed at the shoreline. Due to their short alongshore wavelength and small incident wave angle, gravity waves were discarded from edge wave theory as they cannot be trapped by refraction and reflection (Gallagher et al., 1971). Although the mechanism was not unraveled, Herbers et al., (1999) observed an increase of wave directional spreading in the surf zone close to the shoreline, with shore-based wave reflection as a potential causing factor. A two-dimensional pattern can arise from the superimposition of incident and reflected waves from an irregular shoreline. The literature is extremely limited on this topic despite it has the potential to impact surf zone currents and, in turn, nearshore morphology.

The striking regularity of beach cusps (see Coco et al., 1999 for a review of existing observations) has attracted a concentrated effort mostly focused on predicting the spacing of the features as a function of the incoming wave conditions and morphology. The modezero subharmonic or synchronous standing edge wave approach was initially proposed for their formation (Guza and Inman, 1975; Huntley and Bowen, 1978; Guza and Bowen, 1981; Inman and Guza, 1982). However, this was challenged by field observations of concurrent cusp evolution and infragravity flow motions (among others, Ciriano et al., 2005) and it was 
concluded that edge waves cannot maintain their spatio-temporal characteristics over durations that match that of cusp formation. Bryan and Coco (2010) observe that beach cusps can cause irregular hydrodynamic patterns occurring at the gravity wave frequency. We propose here that beach cusp morphology can act as a template impacting gravity waves and surf zone hydrodynamic patterns.

At dissipative to intermediate beaches with an alongshore-uniform surf zone, the observed transient circulation is the result of either shear instabilities of the longshore current for oblique waves (Bowen and Holman, 1989) or more commonly from alongshore variations of wave breaking (Clark et al., 2012) in nearly shore-normal waves. In the latter case, this irregular breaking can be forced by random short-crested incident waves (Johnson and Pattiaratchi, 2004; Feddersen, 2014). Dalrymple (1975) and Fowler and Dalrymple et al., (1990) also demonstrated that rip currents (see review by Castelle et al., 2016) can theoretically result from a quasi-standing wave pattern that can be caused by two wave trains of different incidences, though this has not been observed in the field. Where there is a reflective upper beach, the feedback of reflection over irregular morphological swash zone, such as a cuspate pattern, on waves and surf zone circulation remains largely undocumented. Existing studies only mention the short spatio-temporal scaled offshore-oriented jets with a 1-10 m extension and lifetime from $30 \mathrm{~s}$ to minutes resulting from two-dimensional swash flow (Masselink and Pattiaratchi, 1998; Dalrymple et al., 2011; Murray et al. 2013; Castelle et al., 2014). However, considering only one dimension, recent works (Almar et al., 2016; Rocha et al., 2017; Martins et al., 2017) suggest that reflection has the potential to influence waves and currents within and beyond the surf zone. On steep beaches, reflection over such a cuspate pattern could be a missing mechanism influencing surf zone circulation. 
This paper aims to provide new insight into the mechanism influence of incident wave reflection from a rhythmic shoreline on surf zone hydrodynamics. This is done using the wave-phase resolving numerical model SWASH, scaled to a realistic reflective low-tide terraced beach exhibiting well-developed beach cusps. The model is also applied to different idealized morphologies (with or without cusps, terrace or no terrace, gentle or steep beach) and wave forcing (incidence angle, angular and frequency spread) to determine the optimal conditions for this two-dimensional reflection mechanism.

\section{Data and methods}

\subsection{SWASH numerical simulations}

The SWASH model (Zijlema et al., 2011) is a vertical multi-layered model based on non-linear shallow water equations (NLSW) including non-hydrostatic pressure. The SWASH model is now currently used in studies focusing on runup, infragravity wave dissipation and energy transfer (Rijnsdrop et al., 2015, De Bakker et al., 2014, 2016), wavedriven circulation and dissipation due to wave breaking in the nearshore area (Guimarães et al., 2015, Medellin et al., 2016, Nicolae Lerma et al., 2017). Model performances has been demonstrated reproducing controlled and idealized conditions (Smit et al., 2013, 2014; Ruju et al., 2014; Rijnsdorp et al., 2014, 2015, 2017; Suzuki et al., 2017) and for schematic 1D profile configurations (Torres-Freyermuth et al., 2012; De Bakker et al., 2014). Only recently was the model applied and demonstrated good skills in 2D or 3D (multilayered mode) simulating complex real cases (e.g. Guimarães et al. 2015; Gomes et al., 2016; Nicolae Lerma et al., 2017).

In this study, the SWASH model is used in a 2 vertical layers 2D mode configuration using the Keller box scheme (Lam and Simpson, 1976) for approximation of the pressure gradients in the vertical momentum equations (Stelling and Zijlema, 2003). This model 
setup gives good dispersive properties even for low vertical resolution (Zijlema et al., 2011). It was reported to provide an accurate description of wave height, wave shape and flow (Smit et al., 2013), while still maintaining reasonable computing time for 2D domains. In this study, the total duration of a given simulation was set to $15 \mathrm{~min}$ for each simulation, with 10 min used for analysis. Based on preliminary simulations showing that the hydrodynamics systematically stabilizes (dynamic equilibrium) within less than 5 minutes, the first 5 minutes were disregarded in the analysis as they correspond to the model spin up. The time step was $0.01 \mathrm{~s}$ and simulation outputs were stored every second, which is enough to robustly analyze reflection effects. Wave breaking was parametrized using HFA (Hydrostatic Front Approximation; see e.g., Kennedy et al., 2000; Tonnelli and Petti, 2012) using default parameters as recommended by Smit et al. (2013).

This SWASH model is used here to investigate the influence of incident wave reflection over a cuspate morphological pattern at very reflective beaches, which are the conditions under which this mechanism is hypothesized to be most significant. Hydromorphological conditions are scaled to the Grand Popo beach (Benin, West Africa) during the March 2014 experiment (Almar et al., 2014; Figure 1). Grand Popo is located on a microtidal open coast exposed to South Atlantic long swells with a small incident wave angle (Almar et al., 2015). The beach has an alongshore-uniform terraced surf zone morphology (Laibi et al., 2014; Abessolo Ondoa et al., 2017) and a reflective upper beach exhibiting a well-developed cuspate pattern with a typical wavelength of about 30-40 m (Senechal et al., 2014). The reference simulation (R0, see Table1) was conducted using surveyed morphology with the measured rhythmic upper beach morphology and an alongshoreaveraged terrace and offshore zone. (Figure 1.b). A control simulation with an alongshoreuniform morphology (average profile replicated alongshore, R1), where cusps have been smoothed out, was also run to isolate their influence on wave reflection. For these two 
simulations, high tide conditions were used, when beach cusps are the most active. Waves measured by an ADCP in 10-m depth were imposed along the offshore boundary. This forcing corresponds to parametric conditions $H s=1.2 \mathrm{~m} \mathrm{Tp}=10 \mathrm{~s}$, Dir $=0^{\circ}$. An analysis of the influence of wave forcing was conducted by varying: incident wave angle (W1 simulations), directional spreading (W2 simulations) and frequency spreading (W3 simulations). Lateral boundary conditions with this realistic morphology were set periodic considering that wave and flow exiting at one boundary enter from the other.

In order to better investigate the reflection mechanism, more controlled simulations were conducted using parametric wave conditions and idealized morphology (C series, Table 1, see Figure 1). The beach profile was generated using the formula proposed by Dean (1991) $Z=a X^{b}$, with $a=0.15, b=2 / 3$. A single cusp of sinusoidal shape is placed on the upper beach, with a wavelength of $30 \mathrm{~m}$ and a $0.4 \mathrm{~m}$ amplitude. A $30-\mathrm{m}$ wide terrace is added in the $\mathrm{C} 0$ simulation, and removed in the $\mathrm{C} 1$ simulation. Upper beach slope was steepened from 0.1 to 0.15 in simulation C2. In these idealized cases, lateral boundaries were parametrized with 200-m sponge width to focus on reflection generation on cuspate morphology at the center of the domain and to avoid generation of potential alongshore variability enforced by lateral boundary conditions. The computation domain extends 1.2 $\mathrm{km}$ and $0.75 \mathrm{~km}$ in the cross-shore and longshore, respectively, with a 1-m spatial resolution. Conditions for the different simulations conducted are summarized in Table 1. 

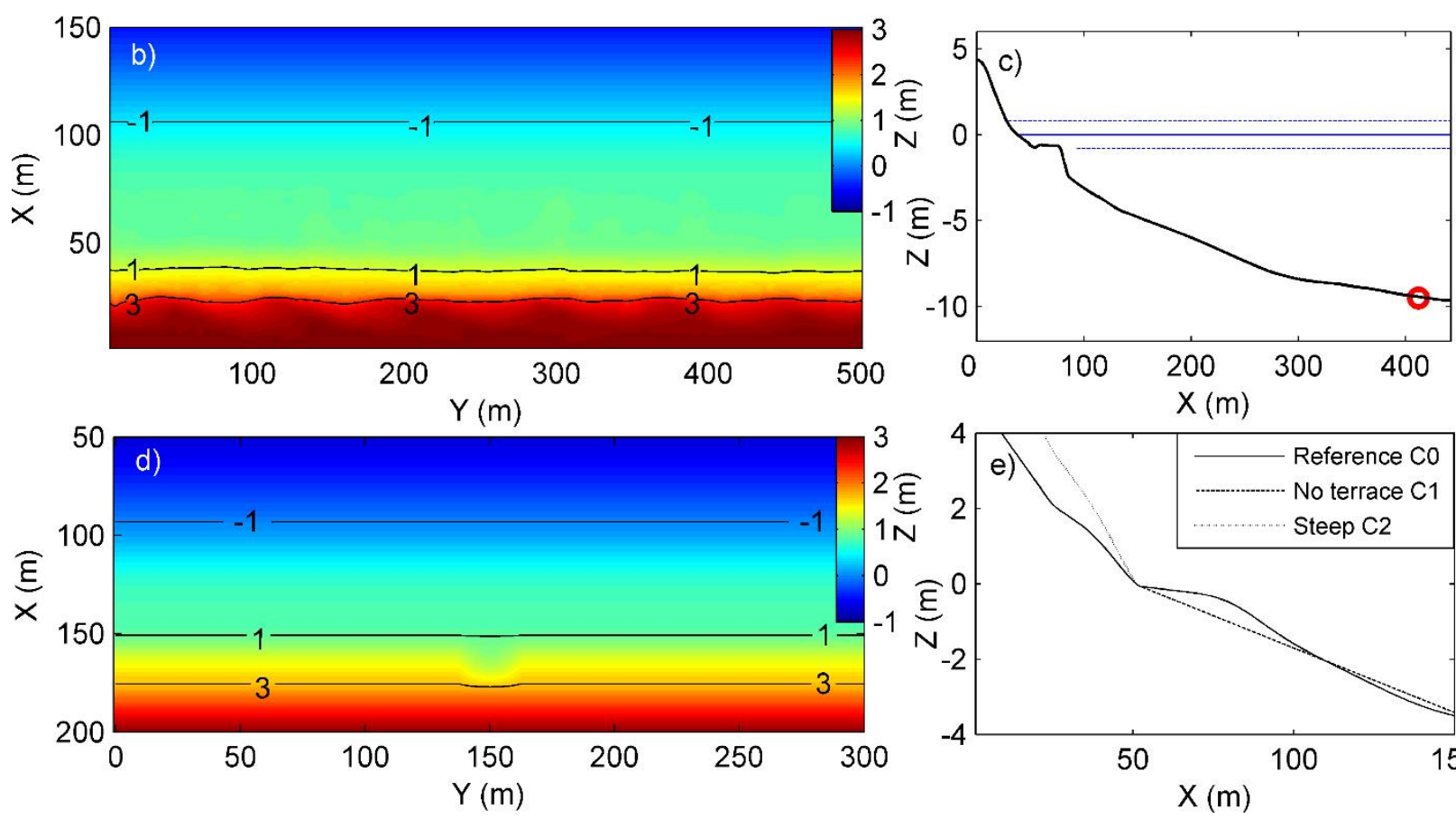

Figure 1: a) Illustration of a low-tide terraced beach with very steep and rhythmic upper beach exposed to long swells, Grand Popo field site (Benin, West Africa). b) Surveyed bathymetry (R0 simulation) with superimposed isobaths as black lines. Surf zone morphology is set alongshore uniform with its c) alongshore-averaged cross-shore profile. Red circle indicates the location of the ADCP, with solid and dashed blue lines indicating 
Table 1: Simulations conducted. Frequency spread is expressed through the JONSWASP enhancement factor $\gamma$. Simulations duration was $15 \mathrm{~min}$. Water level was set constant over all simulations corresponding to high tide conditions ( $1.8 \mathrm{~m}$ above terrace level).

\begin{tabular}{|c|c|c|}
\hline \multirow{2}{*}{$\begin{array}{l}\text { Realistic } \\
\text { conditions }\end{array}$} & R0 & Waves measured at ADCP, surveyed bathymetry (cusps) \\
\hline & R1 & Waves measured at ADCP, uniform bathymetry (no cusps) \\
\hline \multirow{3}{*}{$\begin{array}{l}\text { Test on } \\
\text { incoming } \\
\text { waves }\end{array}$} & W1 & $\begin{array}{l}\text { Direction: } H s=1.2 \mathrm{~m} \text { and } T p=10 \mathrm{~s}, \operatorname{Dir}=0,5,15^{\circ}, \text { DirSpread }=15^{\circ} \text {, } \\
\text { JONSWASP } \gamma=3.3\end{array}$ \\
\hline & W2 & $\begin{array}{l}\text { Directional spreading: } H s=1.2 \mathrm{~m} \text { and } T p=10 \mathrm{~s}, \text { Dir }=5^{\circ} \text {, DirSpread }=5 \text {, } \\
15,40^{\circ} \text {, JONSWASP } \gamma=3.3\end{array}$ \\
\hline & W3 & $\begin{array}{l}\text { Spectral spreading: } H s=1.2 \mathrm{~m} \text { and } T p=10 \mathrm{~s} \text {, Dir }=5^{\circ} \text {, DirSpread }=15^{\circ} \text {, } \\
\text { JONSWASP } \gamma=1,3.3,10\end{array}$ \\
\hline \multirow{4}{*}{$\begin{array}{l}\text { Test on } \\
\text { idealized } \\
\text { single cusp }\end{array}$} & $\mathrm{C} 0$ & $H s=1.2 \mathrm{~m}, T p=10 \mathrm{~s}$, Dir $=0^{\circ}$, Terrace \\
\hline & $\mathrm{C} 1$ & $H s=1.2 \mathrm{~m}, T p=10 \mathrm{~s}, \operatorname{Dir}=0^{\circ}$, No terrace \\
\hline & $\mathrm{C} 2$ & $H s=1.2 \mathrm{~m}, T p=10 \mathrm{~s}$, Dir $=0^{\circ}$, upper beach slope 0.15 instead of 0.1 \\
\hline & C3 & $H s=1.2 \mathrm{~m}, T p=10 \mathrm{~s}$, Dir $=0,20 \mathrm{~m}$ cusp, instead of $30 \mathrm{~m}$ \\
\hline
\end{tabular}

2.2 Generation of wave forcing at the boundary

The role of incident wave characteristics was also addressed. For a better control, the SWASH built-in tool was not used to generate incident wave conditions from measured spectrum. Instead, this was done by generating surface elevation timeseries representing a JONSWAP spectrum (Eq. 1), which allowed us to modify wave characteristics such as directional and spectral spreading. 
$S(f)=\frac{\alpha g^{2}}{f^{5}} \exp \left[-\beta \frac{f_{p}^{4}}{f^{4}}\right] \gamma^{\alpha}$

where $\alpha=\exp \left[-\frac{\left(f-f_{p}\right)^{2}}{2 f_{p}^{2} \sigma^{2}}\right], \sigma=\left\{\begin{array}{l}0.07 \text { if } f \leq f \\ 0.09 \text { if } f>f_{p}\end{array}, \beta=5 / 4, \gamma\right.$ is the enhancement factor and stands for the frequency spread, with a typical value of $3.3, \alpha$ is related to wind speed and fetch length with typical value of 0.01 and $\mathrm{f}$ and $f_{p}$ are wave and peak wave frequencies. The amplitude $A_{\text {Jonswap }}(f)$ of the wave components ( 200 here) is reconstructed from the JONSWAP spectrum, considering a random phase $\varphi$, and wave angle is reconstructed using a phase lag along the offshore boundary. A directional spread is created using a random angle $\operatorname{dir}_{\text {Gaussian }}(f)$ with Gaussian distribution around the peak direction.

$\operatorname{Eta}(y, t)=A_{\text {Jonswap }}(f) \cos \left(2 \pi t f+\varphi-2 \pi f \sin \left(\frac{\operatorname{dir}_{G a u s s i a n}(f) y}{c_{f}}\right)\right.$

with $c_{f}$ being the linear phase celerity which depends on local depth, and y the distance alongshore from the reference point.

\subsection{Separation of incoming and outgoing waves}

The skill of the Radon Transform (RT) to separate incoming and outgoing waves was shown recently using numerical modelling and remotely sensed video and LiDAR data (Almar et al., 2014, 2016; Martins et al., 2017). The RT $R(\rho, \theta)$ of a two-dimensional field $\eta(x, y)$ (Radon, 1917; Deans, 1983; Duda and Hart, 1972) corresponds to a polar projection and can be defined as: 
$R(\rho, \theta)=\oiint \eta(x, t) \delta(x \cos \theta+t \sin \theta-\rho) \mathrm{d} x \mathrm{~d} t$

where $\delta$ is the Dirac delta function, $\theta$ and $\rho$ are the angle and distance from origin of the integration line defined as $\rho=x \cos \theta+y \sin \theta$. The origin is the center of the two-dimensional field. The Radon transform $R(\rho, \theta)$ is defined for all possible values of $\theta$ from [0 to $\left.180^{\circ}\right]$ and $\rho$ from 0 to the diagonal length. The original field $\eta(x, y)$ can be back projected using the Inverse Radon Transform at selected range of $\theta$ values including incoming $\eta_{\operatorname{In}}(x, t)$ $\left[1^{\circ}, 89^{\circ}\right]$ and outgoing $\eta$ out $(x, t)$ angles:

$\eta_{I n}(x, t)=\int_{-\infty}^{+\infty} \int_{1}^{89} R(\rho, \theta) \mathrm{d} \theta \mathrm{d} \rho$

$\eta_{\text {Out }}(x, t)=\int_{-\infty}^{+\infty} \int_{91}^{179} R(\rho, \theta) \mathrm{d} \theta \mathrm{d} \rho$

This is illustrated in Figure 2 where incoming and outgoing waves are separated from a complex surface elevation field (Figure 2.a). Reflected waves in Figure 2.c are substantially more variable alongshore than the incident waves which are rather uniform (Figure 2.b). 

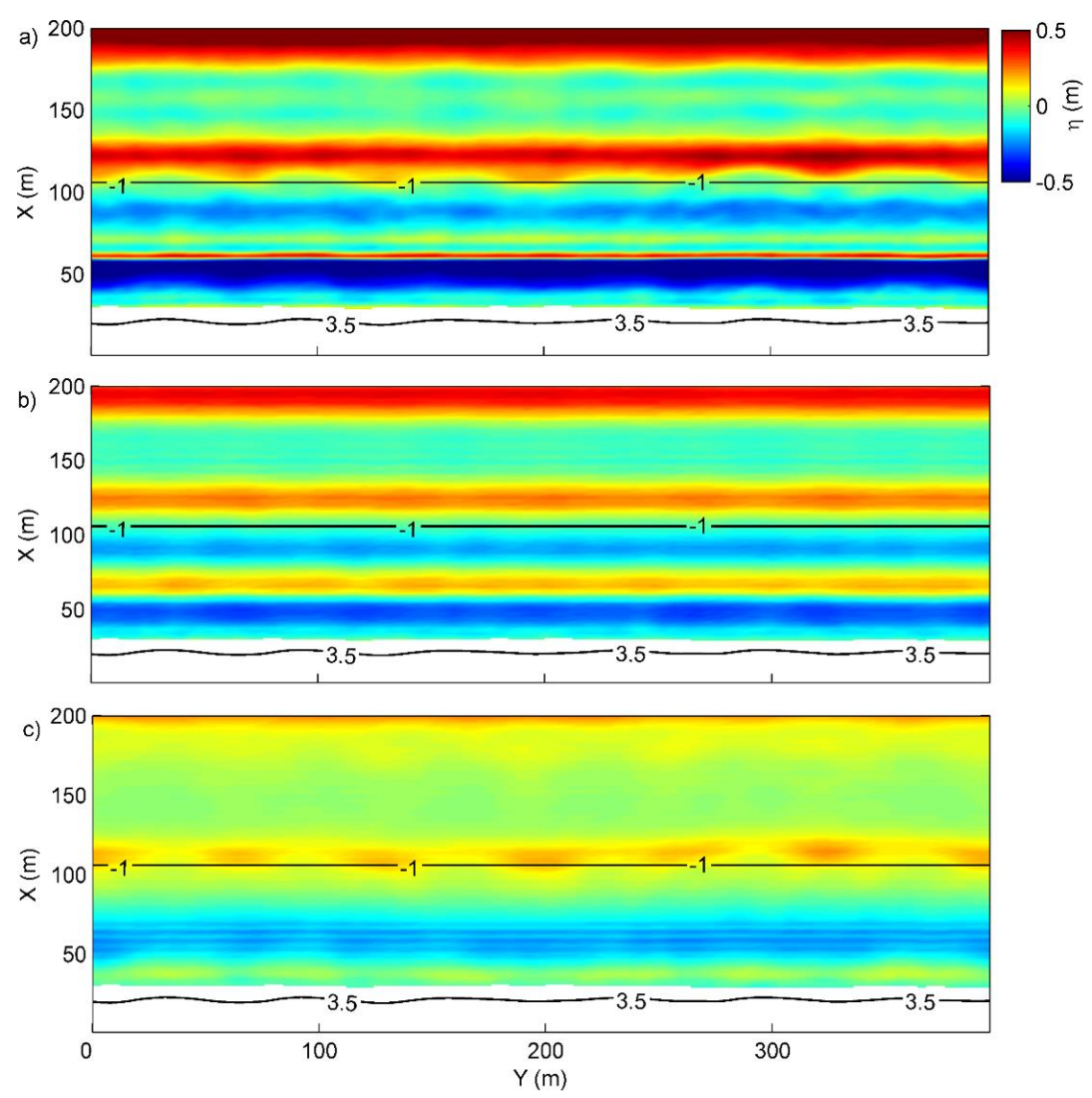

Figure 2: Illustration of the RT method for the separation of b) incoming and c) outgoing waves from a) total surface elevation. Black lines are isobaths, showing the outer limit of the terrace $(-1 \mathrm{~m})$ and the upper beach morphology $(+3.5 \mathrm{~m})$.

\section{Results}

\subsection{Realistic simulations}

To illustrate the influence of reflection over an irregular swash zone, two simulations with realistic wave and morphological conditions were conducted, with and without cusps. The first column of Figure 3 shows the reflection of shore-normal waves over the realistic morphology where alongshore irregularities have been removed (R1 simulation, Table 1). Reflection is purely shore-normal with no directional spread of reflected waves. In the 
second column of Figure 3, the realistic morphology (Figure 1.b) with beach cusps is considered (R0). The reflection of incoming waves over the cuspate pattern generates an irregular reflected wave. An anomaly on the total wave field is observed both in the longshore and cross-shore directions and extends offshore of the breaking zone which is located over the terrace. Regular nodes and anti-nodes highlight the presence of standing waves.
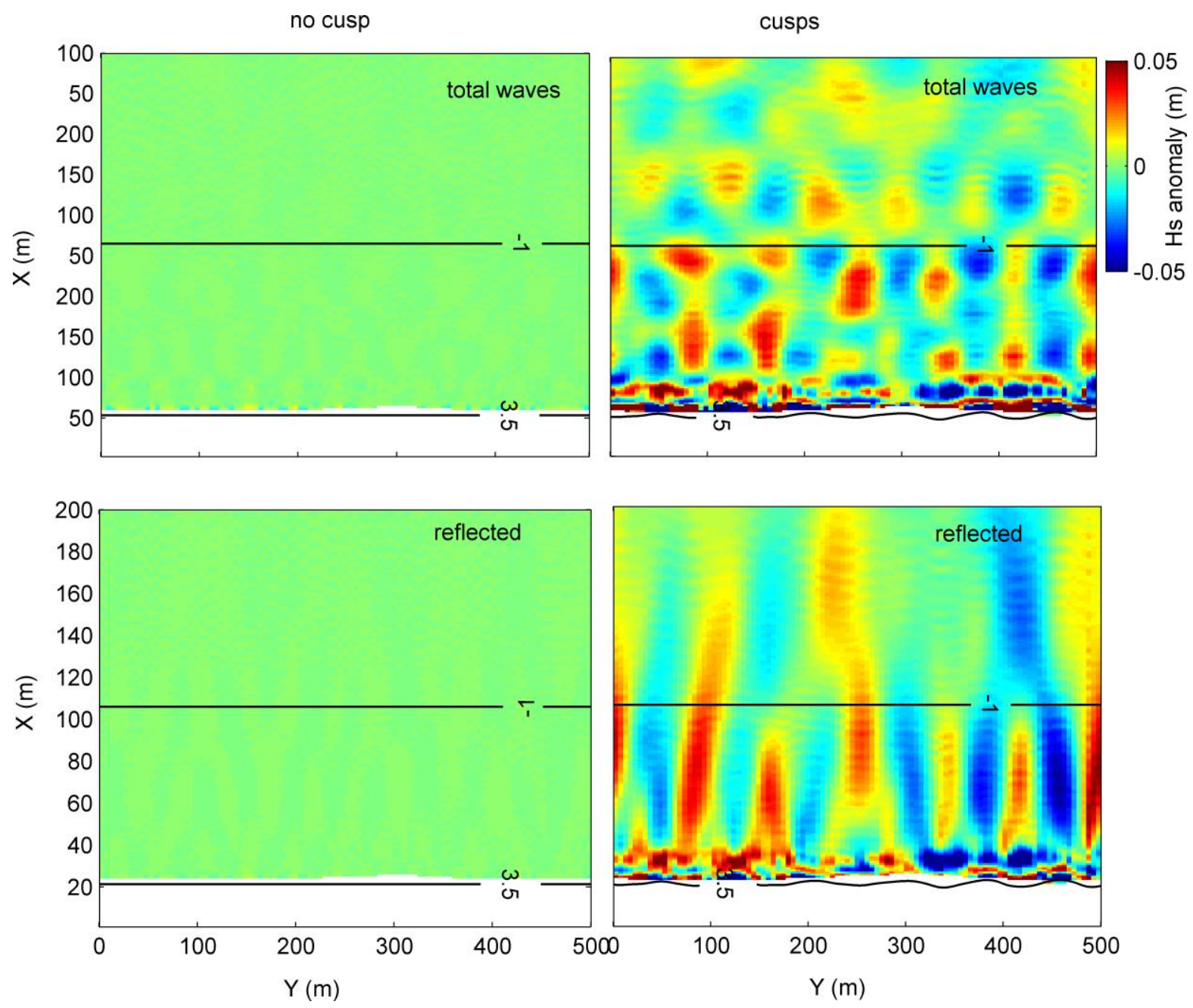

Figure 3. 10-min averaged $H s$ alongshore anomaly ( $H s$ minus alongshore-averaged $H s$ ) with no cusp (left) and realistic (right) morphologies (R1 and R0 simulations, Table 1), for total 
waves (incoming and reflected) in the upper panels and reflected waves only (using Eq. 5) in the lower panels. Black lines show isobaths.

\subsection{Influence of morphology}

To investigate the influence of different morphologies on wave reflection, more controlled simulations were conducted with synthetic waves and bathymetry. Shorenormal waves were propagated over an alongshore-uniform low-tide terrace and a single cusp (C0 simulation in Table 1), to better isolate the two-dimensional reflection mechanism. Figure 4 shows a sequence of incoming, outgoing, and total surface alongshore anomaly every $5 \mathrm{~s}$ during the reflection of an individual wave. While incoming waves are rather uniform alongshore, reflected waves propagate in all direction, making a half circle. The differences of celerity values of these reflected waves induce a deformation of the wave propagation circle; the wave going slower on the terrace than offshore. It is noteworthy that the reflected wave wavelength is longer than the incident wave length, with the beach acting as a low pass-filter (Battjes, 1974). Over a wave period, superposition of the next wave with the reflected one generates a surface elevation anomaly.

The influence of different morphological parameters was tested using averaged anomalies of $H s$, with the previous configuration ( $\mathrm{CO}$ ) as a baseline. The influence of reflection clearly appears in Figure 5.a with the presence of nodes and antinodes from the interaction between incoming and outgoing waves. Most of the standing wave energy is localized off the cusp, though another part spreads and is distributed alongshore. Antinodes and nodes also appears at the shoreline, which induces an alongshore anomaly in the runup (see Figure 5.b). If the terrace is removed (C1), no substantial change is observed in Figure 5.b and the alongshore anomaly is still there. Almar et al. (2016) found that the main differences arise from the increase in the upper beach slope from 0.1 to 0.1 . 
The runup wavelength can be visually identified as the alongshore distance between two maxima or minima of the runup amplitude anomaly. It can be seen that the increase of the upper beach slope reduces the wavelength from $\sim 70 \mathrm{~m}$ to $30-40 \mathrm{~m}$. Interestingly, this wavelength does not depend on the cusp alongshore dimension, which can change from 30 to $20 \mathrm{~m}$ (C3) with little impact.
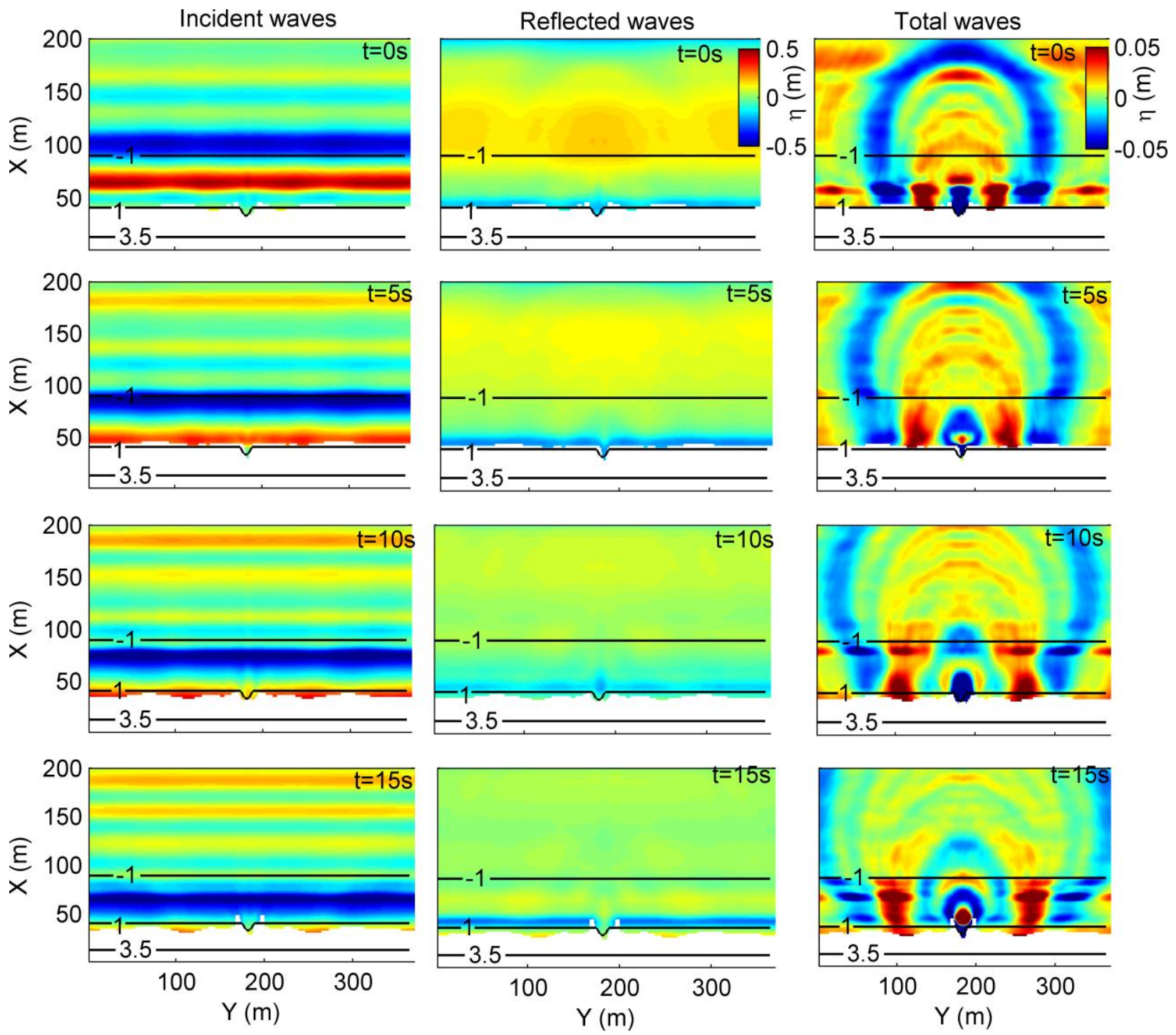
Figure 4: Sequence of surface elevation fields for incoming waves (left), reflected waves (center) and total anomaly (right), for random waves $\left(H s=1.2 \mathrm{~m}, T p=10 \mathrm{~m}, \operatorname{Dir}=0^{\circ}\right.$ ) and single cusp morphology ( $\mathrm{C} 0$ simulation, see Table 1). Black lines show isobaths.
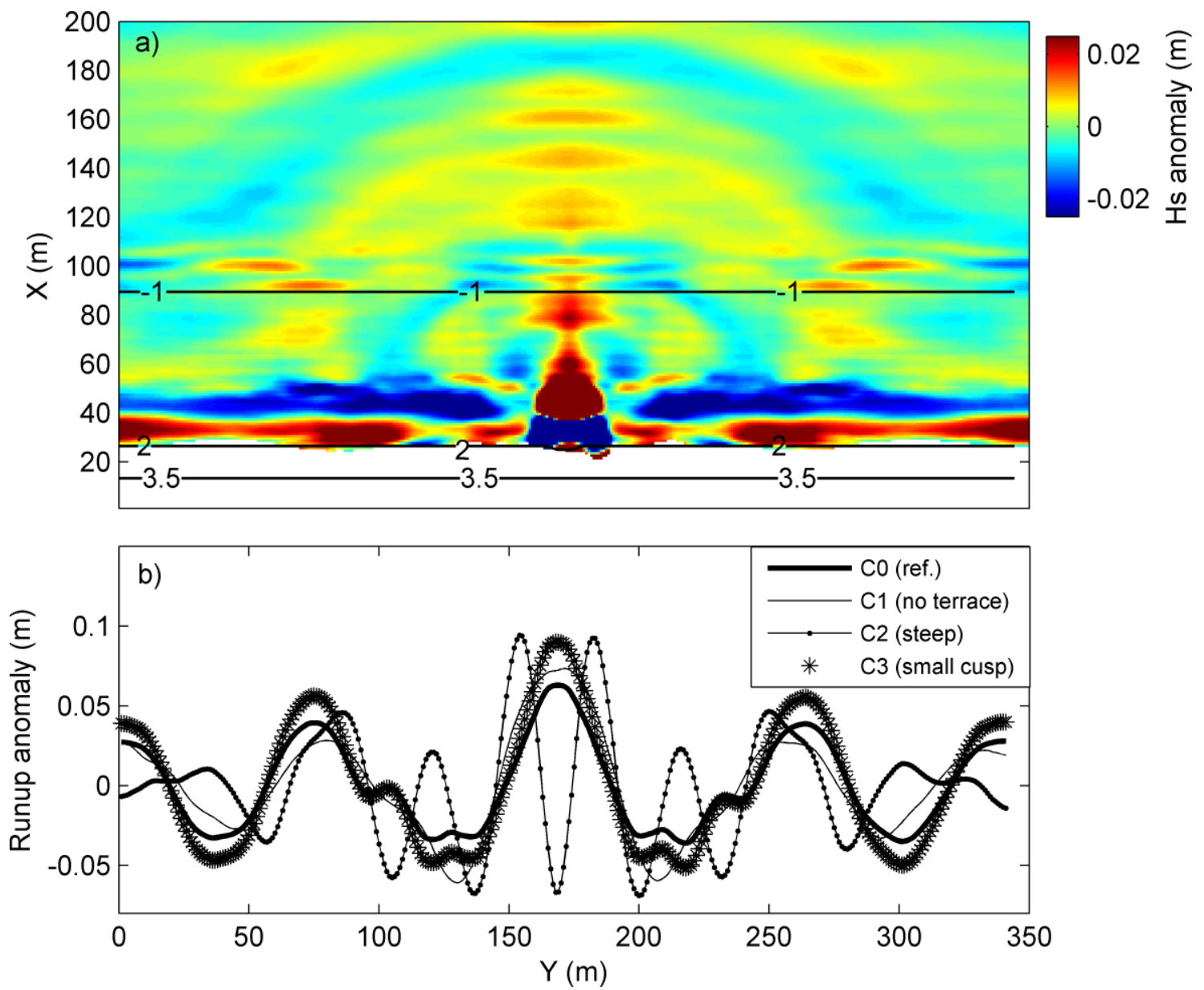

Figure 5: a) Average $H s$ anomaly for the single 30-m cusp morphology ( $\mathrm{C} 0$ simulation, see Table 1) and b) runup anomaly for different morphologies: C0 (solid thick), C1(no terrace, solid thin), C2 (steeper slope, solid with dots) and C3 (shorter cusp, stars). In a), black lines show isobaths.

3.3 Influence of incident waves 
Longer wave period increases unidirectional reflection (Battjes, 1974). But how the efficiency of the two-dimension reflection mechanism evolves with wave incidence angle and spectrum width (frequency and angle) is not documented. To investigate this, the angle of incidence was varied from shore normal $0^{\circ}$ to $5^{\circ}$ and $15^{\circ}$ (W1 series), directional spreading varied from narrow $5^{\circ}$, to wide $40^{\circ}$ (W2 series), and spectral spreading changed through the JONSWAP $\gamma$ factor from 1 (wide), 3.3 to 10 (narrow) (W3 series). This was done by forcing at the offshore boundary with the time series of surface elevation from the method described in Section 2.2. Instantaneous surface elevation fields are illustrated in Figure 6. The realistic upper beach topography is used here. The amplitude of resulting standing waves is computed as the cross-shore averaged alongshore anomalies. Figure 6 shows that the standing wave amplitude increases when incident waves are shore-normal. This is due to the two-dimensional reflection only, as previous studies from a uniform swash zone on a natural beach (Taira and Nagata, 1968; Suhayda, 1974) and sea wall (Sutherland and O'Donoghue, 1998) indicate that incident angle induces a phase shift on the reflected waves without changing standing wave amplitude. Figure 6 also shows that amplitude increases with narrow banded spectra and angular incident waves, which ensure more coherency between incident and reflected wave phases. 

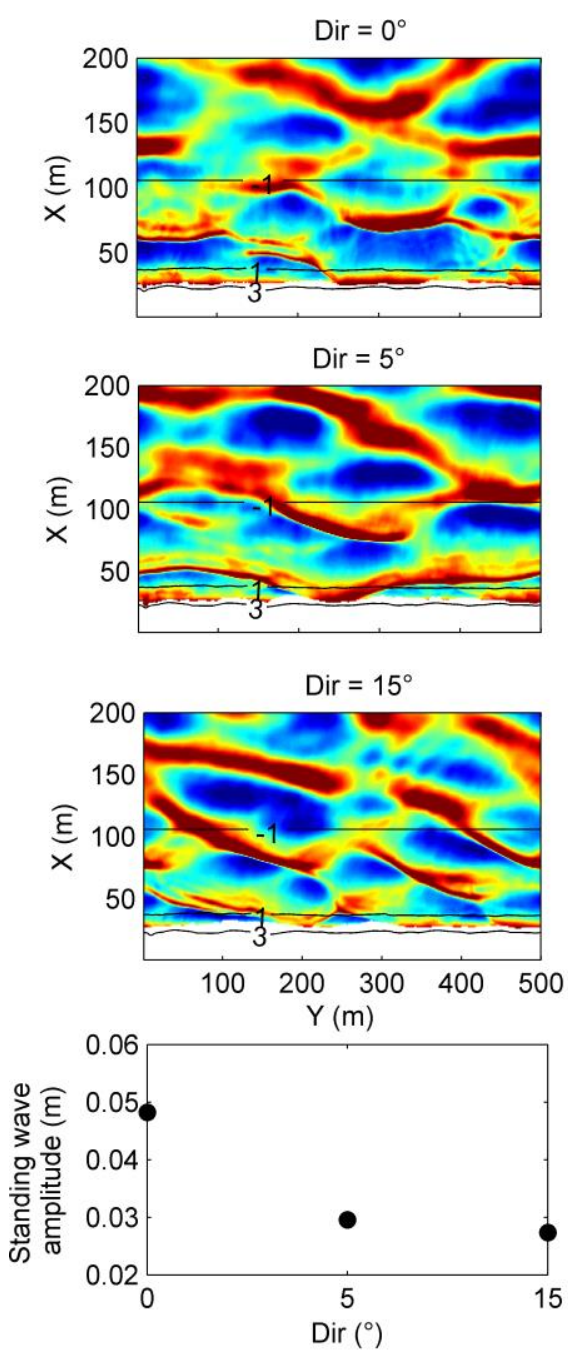
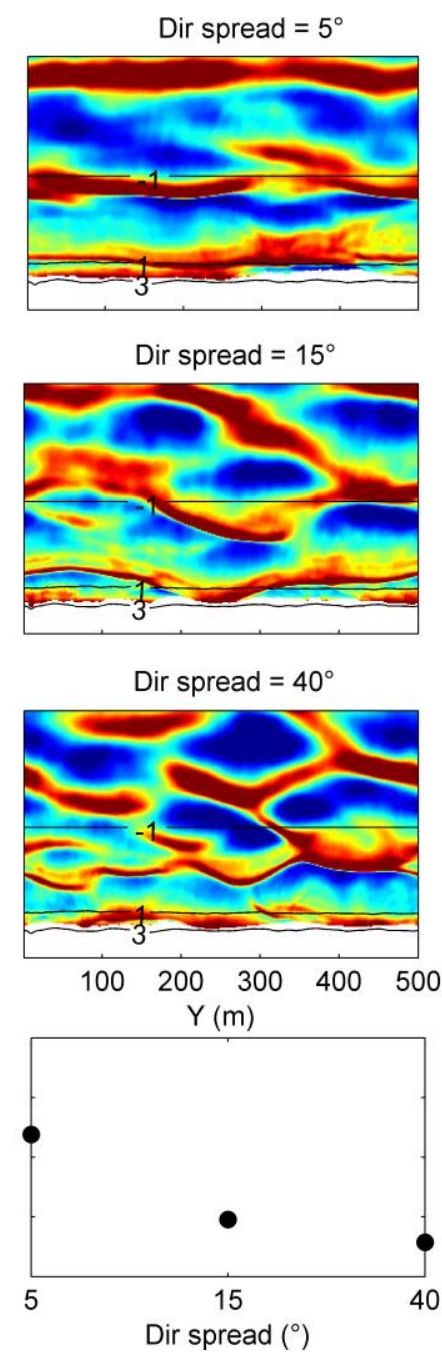
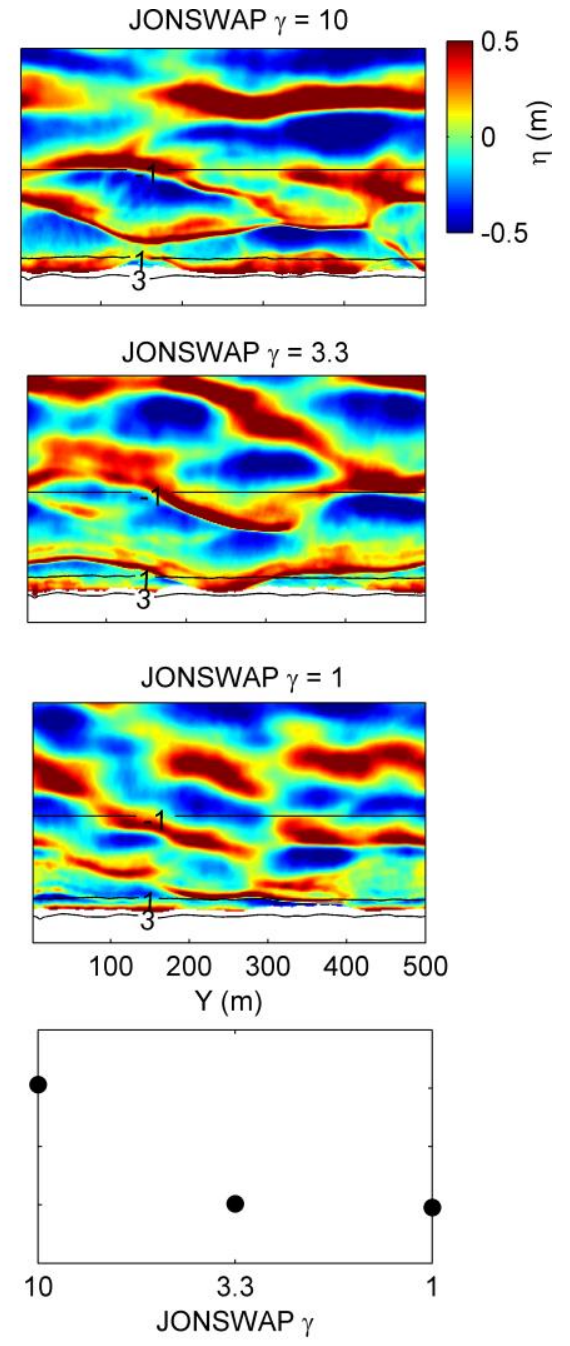

Figure 6: Influence of wave forcing on standing wave amplitude. Instant surface elevation fields in upper panels illustrate different incident waves, and the resulting amplitude of standing waves are shown in lower panels. In the first column, incident direction is changed from 0 to 5 to $15^{\circ}$ (W1 simulations, see Table 1). In the second column the directional spread is changed from 5 to 15 to $40^{\circ}$ (W2 simulations). In third column frequency spread (enhancement factor $\gamma$ in the JONSWAP formula) is changed from 10 (narrow) to 3.3 to 1 (wide) (W3 simulations). Black lines show isobaths. See W series in Table 1 for more detail on simulations. 


\section{Discussion}

On steep beaches, resonance of the underlying morphology with particular frequencies can excite progressive subharmonic edges waves resulting in a quasi-standing edge wave (Guza \& Inman, 1975, Guza \& Bowen, 1976; extended for oblique waves in Guza and Chapman, 1979). This subharmonic resonance does not occur with weakly reflected incident waves (Guza \& Bowen, 1976). Our numerical simulations show that standing waves can also form from the mechanism of reflection over an irregular swash zone, even for shore-normal waves. This is due to the linear superimposition of incoming and twodimensional reflected gravity waves, and not the combination of opposite progressive infragravity waves. The mechanism is different but the resulting standing wave mimics the spatio-temporal characteristics of a standing subharmonic edge wave. Our results show that this reflection-induced standing pattern is controlled, similarly to subharmonic edge waves, by the upper beach slope and incoming wave characteristics, rather than by the perturbation dimension.

A number of studies have suggested that edge waves are responsible for the initiation of cusps (Huntley and Bowen, 1978; Sallenger, 1979) but many have failed to establish this link (Holland and Holman, 1996; Masselink et al., 1997; Almar et al., 2008). Some limitations of the edge wave model are that once the cusps develop they tend to suppress edge wave motion and the evolution of their spatio-temporal characteristics are not compatible with cusp lifetime (Guza and Bowen, 1981; Ciriano et al., 2005). This is not the case with reflection-induced standing gravity waves whose characteristics would grow with the development of the cusps amplitude, which triggers and spreads energy in two dimensions, through a supposed positive feedback. Coco et al., (2001) noticed that beach cusps form most readily when narrow-banded waves are normally incident (Longuet- 
Higgins and Parkin, 1962; Sallenger, 1979; Guza and Bowen, 1981) which are the optimal conditions found in our sensitivity analysis for the reflection-based mechanism. Swashinduced reflection can be a new mechanism for the initiation of a cuspate pattern around a morphological perturbation, in a similar way to that which Reniers et al. (2004) suggest for the surf zone where wave group patterns could be sufficiently long lasting to perturb an initially alongshore uniform beach in a quasi-periodic way, with appropriate scales.

To the authors' knowledge, the feedback of irregular reflected waves on surf zone dynamics was not accounted for by studies dealing with surf zone circulation and rip current occurrence (e.g. Johnson and Pattiaratchi, 2004; Feddersen, 2014; see also a review by Castelle et al., 2016). Recently, unidirectional studies of Almar et al., (2016) and Martins et al. (2017) demonstrated the role played by reflection on waves breaking and the intensification of the undertow. When considering reflection over an irregular swash zone this mechanism has the potential to influence a two-dimensional circulation. A regular pattern of pulsating rip currents can be forced, similarly to that shown theoretically by Dalrymple (1975) with two trains of incident waves of different incidence. Figure 7 illustrates the generation of offshore-oriented currents jets for realistic conditions (R0 simulation, Table 1). These current anomalies propagate off the surf zone where they can even be reinforced by the interaction with following wave breaking (Figure 7.c). Figure 8 shows the amplitude of vorticity generated by the reflection over a single cusp morphology with shore-normal waves ( $\mathrm{C} 0$ simulation, Table 1). It is noteworthy that this estimates the amplitude of the pulses and not the average intensity of the circulation. The resulting regular pattern is striking, with maxima every $\sim 30-40 \mathrm{~m}$. More analyses are needed with concurrent synoptic observations of surf zone currents across both reflective and intermediate surf zones (e.g. Haller et al., 2016; Derian and Almar, 2017). However, this study suggests that wave reflection over a morphologically irregular swash zone provide a 
mechanism for affecting surf zone circulation variability, such as rip currents, particularly at sites with a steep upper beach.
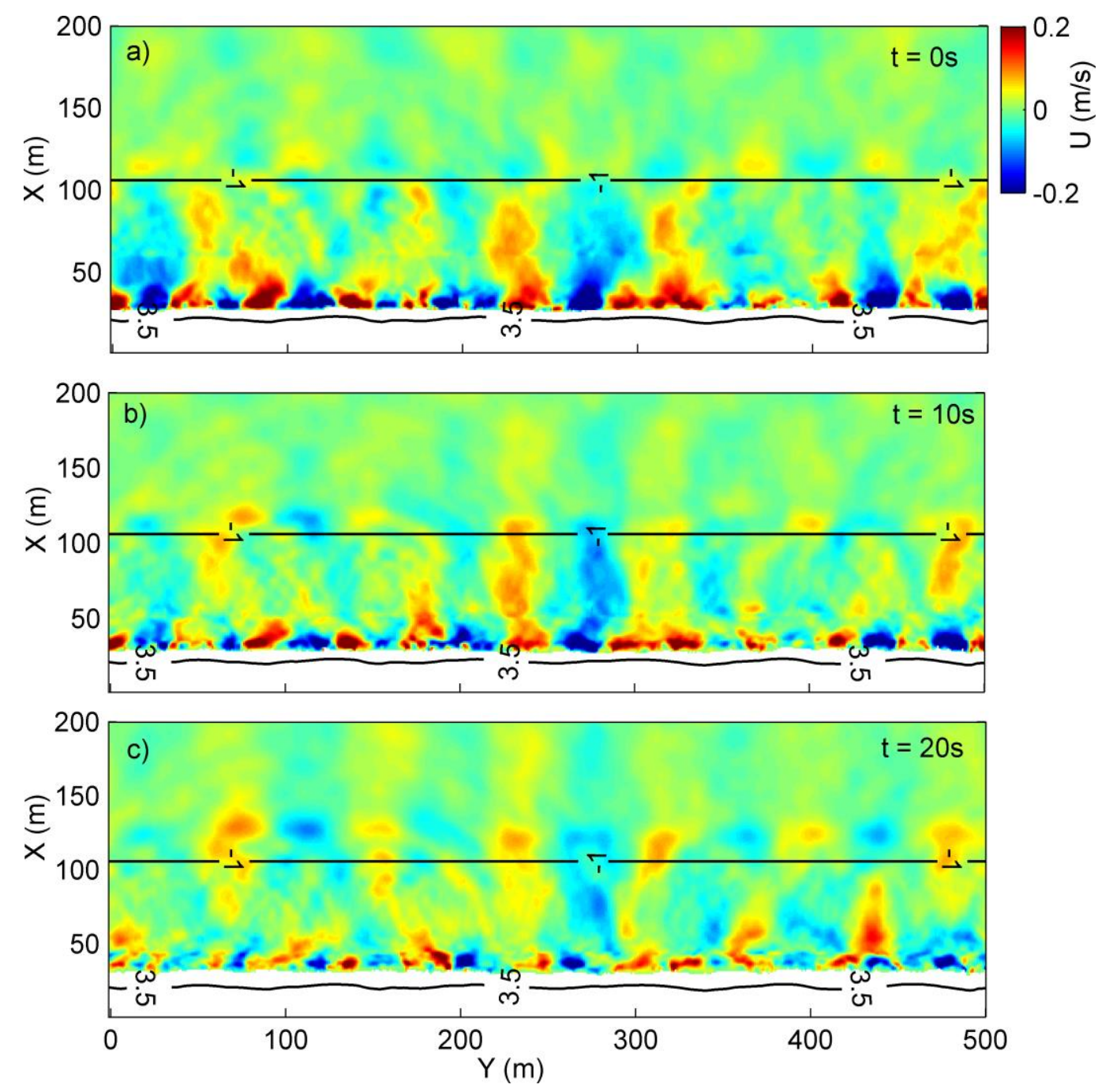

Figure 7: Sequence of the alongshore anomaly of cross-shore current fields for measured shore-normal waves over a realistic bathymetry (R0 simulation, Table 1). Black lines show isobaths. 


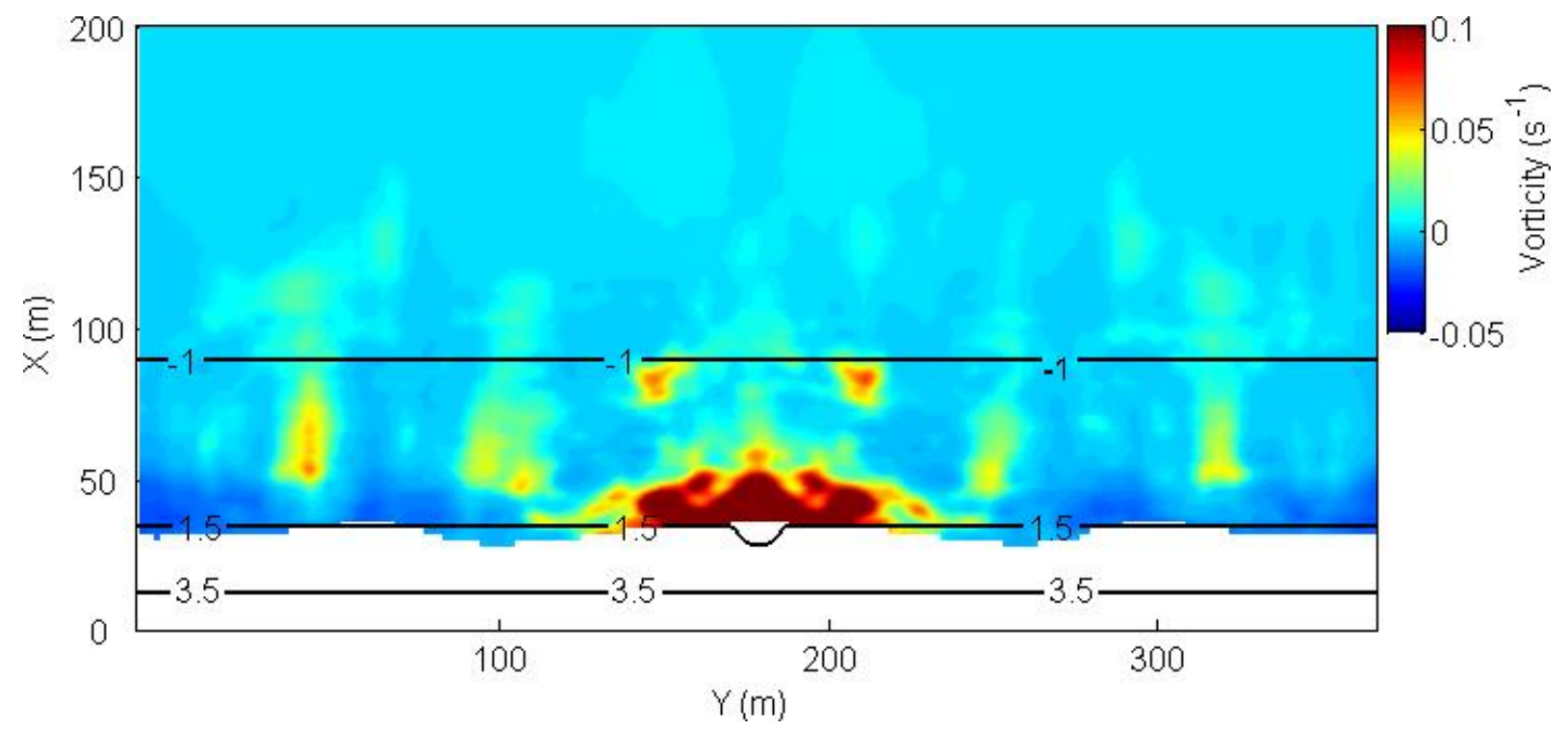

Figure 8: Alongshore anomaly of vorticity variability $(4 \sigma)$ field for the single idealized cusp case, shore-normal waves (C0 simulation, Table 1). Black lines show isobaths.

\section{Conclusions}

The impact of alongshore-variable incident wave reflection over a rhythmic swash zone morphology on the surf zone was explored. Simulations were conducted using the wave-phase resolving SWASH model scaled on realistic reflective conditions of a low-tide terraced beach exhibiting beach cusps. Results show that this reflection mechanism drives a significant surf zone variability. A standing wave pattern is generated with characteristics mimicking a subharmonic edge wave. The morphological control of this standing wave wavelength is dominated by upper beach slope rather than by cusp dimensions. The efficiency of this mechanism increases with shore-normal, narrow-banded waves. Our study suggests that wave reflection over steep beaches could be a mechanism for the development of rhythmic morphological features such as beach cusps and rip current occurrence. 


\begin{abstract}
Acknowledgements
The Grand Popo experiment was supported by French INSU/CNRS EC2CO-LEFE/IRD, UNESCO co-chair ICPMA/IPB. We are indebted to the naval services of Benin at Grand Popo for their logistic support during the field experiment and for allowing the installation of the permanent video system on their semaphore. This research has received support from French grants through ANR (COASTVAR: ANR-14-ASTR-0019). We thank Giovanni Coco for his thorough reading of this manuscript.
\end{abstract}

\title{
References
}

Abessolo Ondoa, G., Bonou, F., Tomety, F.S., Du Penhoat, Y., Perret, C., Degbe, C.G.E, Almar, R., 2017. Event to seasonal and inter-annual coastal evolution at Grand Popo, Benin. Water, 9(6), 447; doi:10.3390/w9060447

Almar, R., Almeida, P., Blenkinsopp, C., Catalan, P., 2016. Surf-swash interactions on a lowtide terraced beach. Journal of Coastal Research, SI 75: 348-352

Almar, R., Kestenare, E., Reyns, J., Jouanno, J., Anthony, E.J., Laibi, R., Hemer, M., Du Penhoat, Y., Ranasinghe, R., 2015. Response of the Bight of Benin (Gulf of Guinea, West Africa) coastline to anthropogenic and natural forcing, Part1: Wave climate variability and impacts on the longshore sediment transport, Continental Shelf Research, 110, 48-59

Almar, R., Michallet, H., Cienfuegos, R., Bonneton, P., Ruessink, B.G. and Tissier, M., 2014. On the use of the Radon Transform in studying nearshore wave dynamics, Coastal Engineering, 92, 24-30

Almar, R., Du Penhoat, Y., Honkonnou, N., Castelle, B., Laibi, R., Anthony, E., Senechal, N., Degbe, G., Chuchla, R., Sohou, Z., Dorel, M., 2014. The Grand Popo experiment, Benin, Journal of Coastal Research, SI 70, 651-656, ISSN 0749-0208 
Almar, R., Coco, G., Bryan, K.R., Huntley, D.A., Short, A.D., Senechal. N., 2008. Video observations of beach cusp morphodynamics, Marine Geology. 254, 216-223

Battjes, J.A., 1974. "Surf similarity", Proceedings 14th International Conference on Coastal Engineering, pp. 466-480, doi:10.9753/icce.v14

Bowen, A.J., Holman, R.A., 1989. Shear instabilities of the mean longshore current, 1, Theory, 3. Geophys. Res., 94, 18,023-18,030

Bryan, K.R., Bowen, A.J., 1996. Edge wave trapping and amplification on barred beaches. Journal of Geophysical Research, 101, C3, 6543-6552

Bryan, K.R., Coco, G., 2010. Observations of nonlinear runup patterns on plane and rhythmic beach morphology. Journal of Geophysical Research, 115, C9, DOI: 10.1029/2009JC005721

Castelle, B., du Penhoat, Y., Almar, R., Anthony, E., Lefebvre, J-P., Laibi, R., Chuchla, R., Dorel, M., Senechal, N., 2014. Flash rip dynamics on a high-energy low-tide-terraced beach (Grand Popo, Benin, West Africa), Journal of Coastal Research, SI 70, 633-638, ISSN 0749-0208

Castelle, B., Scott, T., Brander, R.W., McCaroll, R.J., 2016. Rip current types, circulation and hazard Earth-Science Reviews, 163, 1-21.

Ciriano, Y., Coco, G., Bryan, K.R., Elgar, S., 2005. Field observations of swash zone infragravity motions and beach cusp evolution, J. Geophys. Res.,110, C02018, doi:10.1029/2004JC002485

Clark, D.B., Elgar, S., Raubenheimer, B., 2012. Vorticity generation by short-crested wave breaking, Geophys. Res. Lett.,39, L24604, doi:10.1029/2012GL054034

Coco, G., Huntley, D.A., O'Hare, T.J., 2001. Regularity and randomness in the formation of beach cusps, Mar. Geol., 178, 1-9. 
Coco, G., O'Hare, T.J., Huntley, D.A., 1999. Beach cusps: A comparison of data and their formation. Journal of Coastal Research, 15(3), 741-749

Contardo, S., and Symonds, G., 2013. Infragravity response to variable wave forcing in the nearshore, J. Geophys. Res. Oceans, 118, 7095-7106, doi:10.1002/2013JC009430

Dalrymple, R.A., 1975. A mechanism for rip current generation on an open coast, J. Geophys. Res., 80(24), 3485-3487, doi:10.1029/JC080i024p03485.

Dalrymple, R.A., MacMahan, J.H., Reniers, A.J.H.M., Nelko, V., 2011. Rip currents, Annu. Rev. Fluid Mech., 43, pp. 551-581

De Bakker, A.T.M., Tissier, M.F.S, Ruessink, B.G., 2014. Shoreline dissipation of infragravity waves, Continental Shelf Research, 72 73-82.

Dean, R.G., 1991. Equilibrium beach profiles: characteristics and applications. Journal of Coastal Research 7(1), 53-84

Deans, S., 1983. The Radon transform and some of its applications, 1st Edition. John Wiley \& Sons, New York, 289 p, ISBN 13: 9780471898047

Derian, P., Almar, R., 2016. Wavelet-based Optical Flow Estimation of Instant Surface Currents from Shore-based and UAV Video. IEEE Transactions on Geoscience and Remote Sensing 55 (10), 5790-5797

Duda, R.O., Hart, P.E., 1972. Use of the Hough Transformation to Detect Lines and Curves in Pictures, Comm. ACM, 15, 11-15.

Elgar, S., Herbers, T., Guza, R., 1994. Reflection of ocean surface gravity waves from a natural beach. J. Physical. Oceanogr., 24(7), 1503-1511.

Fowler, R.E., Dalrymple, R.A., 1990. Wave-group forced nearshore circulation, in Proceedings of the 22nd International Conference on Coastal Engineering, pp. 729742, Am. Soc. of Civ. Eng., Delft, Netherlands. 
Gallagher, B., 1971. Generation of surf beat by non-linear wave interactions. J. Fluid Mech, $49,1-20$

Gomes, E.R., Mulligan, R.P., Brodie, K.L., McNinch, J.E., 2016. Bathymetric control on the spatial distribution of wave breaking in the surf zone of a natural beach. Coastal Engineering, 116, 180-194.

Guimarães, P.V., Farina, L., Toldo, E., Diaz-Hernandez, G., Akhmatskaya, E., 2015. Numerical simulation of extreme wave runup during storm events in Tramandaí Beach, Rio Grande do Sul, Brazil, Coastal Engineering 95, 171-180.

Huntley, D.A., Bowen, A.J., 1978. Beach Cusps and Edge Waves. Proceedings of the Sixteenth International Conference on Coastal Engineering. ASCE, Long Island NY, pp. 1378-1393

Feddersen, F., 2014. The generation of surfzone eddies in a strong alongshore current. J. Phys. Oceanogr., 44, 600-617

Guza, R.T., Inman, D.L., 1975. Edge Waves and Beach Cusps. Journal of Geophysical Research-Oceans and Atmospheres. 80:2997-3012. 10.1029/JC080i021p02997

Guza, R.T., Bowen, A.J., 1976. Finite-Amplitude Edge Waves. Journal of Marine Research. 34:269-293.

Guza, R.T., Chapman, D.C., 1979. Experimental-Study of the Instabilities of Waves Obliquely Incident on a Beach. Journal of Fluid Mechanics. 95:199-208. $10.1017 / \mathrm{s} 0022112079001427$

Guza, R.T., Bowen, A.J., 1981. On the Amplitude of Beach Cusps. Journal of Geophysical Research-Oceans and Atmospheres. 86:4125-4132. 10.1029/JC086iC05p04125

Herbers, T.H.C., Elgar, S., Guza, R.T., 1999. Directional spreading of waves in the nearshore, Journal of Geophysical Research, 104, C4, 7683-7693

Haller, M.C., Kloster, R., O'Dea, A., 2016. On the imaging of rip currents in X-band radar. American Geophysical Union, Ocean Sciences Meeting 2016, EC11A-01 
Holland, K.T., Holman, R.A., 1996. Field observations of beach cusps and swash motions. Mar. Geol. 134, 77-93

Inch, K., Davidson, M., Masselink, G., Russell, P., 2016. Accurate estimation of wave reflection on a high energy, dissipative beach. J. Coast. Res. SI, 75, 877-881

Inman, D.L., Guza, R.T., 1982. The Origin of Swash Cusps on Beaches. Marine Geology. 49:133-148. 10.1016/0025-3227(82)90033-0

Johnson, D., Pattiaratchi, C., 2004. Transient rip currents and nearshore circulation on a swell-dominated beach, J. Geophys. Res., 109, Article C02026

Kennedy, A.B., Chen, Q., Kirby, J.T., Dalrymple, R.A., 2000. Boussinesq modeling of wave transformation, breaking, and runup. I: 1D, Journal of Waterway, Port, Coastal, and Ocean Engineering 1260 (1) 39-47.

Laibi, R., Anthony, E., Almar, R., Castelle, B., Senechal, N., 2014. Morphodynamic characterisation of the human-impacted Bight of Benin sand barrier coast, West Africa, Journal of Coastal Research, SI 70, 079-083, ISSN 0749-0208

Lam, D.C.L., Simpson, R.B., 1976. Centered differencing and the box scheme for diffusion convection problems. Journal of computational physics, 22(4), 486-500.

Longuet-Higgins, M.S., Parkin, D.W., 1962. Sea waves and beach cusps. Geographical Journal $128,194-201$

Martins, K., Blenkinsopp, C.E., Almar, R., Zang, J., 2017. The influence of swash-based reflection on surf zone hydrodynamics: a wave-by-wave approach. Coastal Engineering, 122, pp. 27-43.

Masselink, G., Pattiaratchi, C., 1998. Journal of Coastal Research, Vol. 14, No. 2, pp. 393-406 Masselink, G., Hegge, B.J., Pattiaratchi, C., 1997. Beach cusp morphodynamic. EarthSurf. Processes Landf. 22, 1139-1155 
Medellín, G., Brinkkemper, J.A., Torres-Freyermuth, A., Appendini, C.M., Mendoza, E.T., Salles, P., 2016. Run-up parameterization and beach vulnerability assessment on a barrier island: a downscaling approach, Nat. Hazards Earth Syst. Sci., 16 167-180.

Mizuguhi, M., 1984. Swash on a natural beach. Coastal Engineering Proceedings, 19, 21561028.

Murray, T., Cartwright, N., Tomlinson, R., 2013. Video-imaging of transient rip currents on the Gold Coast open beaches, J. Coast. Res. SI, 65, pp. 1809-1814

Nicolae Lerma, A., Pedreros, R., Robinet, A., Sénéchal, N., 2017. Simulating wave setup and run-up during storm conditions on a complex barred beach, Coastal Engineering, 123, 29-41, DOI:10.1016/j.coastaleng.2017.01.011

Radon, J., 1917. Uber die bestimmung von funktionen durch ihre integralwerte l'angs gewisser mannigfaltigkeiten. Akad. Wiss., 69, 262-277

Reniers, A.J.H.M., Roelvink, J.A., Thornton, E.B., 2004. Morphodynamic modeling of an embayed beach under wave group forcing, J. Geophys. Res., 109, C01030, doi:10.1029/2002JC001586

Rijnsdorp, D., Smit, P.B., Zijlema, M., Reniers, A.J.H.M., 2017. Efficient non-hydrostatic modelling of 3D wave-induced currents using a subgrid approach, Ocean Modelling, Volume 116, pp 118-133.

Rijnsdorp, D.P., Ruessink, G., Zijlema, M., 2015. Infragravity-wave dynamics in a barred coastal region, a numerical study. Journal of Geophysical Research: Oceans 120, 40684089.

Rijnsdorp, D.P., Smit, P.B., Zijlema, M., 2014. Non-hydrostatic modelling of infragravity waves under laboratory conditions. Coastal Engineering 85, 30- 42. 
Rocha, M.V.L.M., Michallet, H., Silva, P.A., 2017. Improving the parameterization of wave nonlinearities ? The importance of wave steepness, spectral bandwidth and beach slope. Coastal Engineering, 121, 77-89.

Ruju, A., Lara, J.L., Losada, I.J., 2014. Numerical analysis of run-up oscillations under dissipative conditions, Coast. Eng., 86 45-56.

Sallenger, A.H., 1979. Beach cusp formation. Mar. Geol. 29, 23-37

Senechal, N., Laibi, R., Almar, R., Castelle, B., Degbe, G., Du Penhoat, Y., Chuchla, R., Honkonnou, N., 2014. Beach cusp dynamics on a reflective beach, Journal of Coastal Research, SI 70, 669-674, ISSN 0749-0208

Smit, P.B., Zijlema, M., Stelling, G.S., 2013. Depth-induced wave breaking in a nonhydrostatic, near-shore wave model. Coast. Eng., 76 1-16.

Smit, P., Janssen, T., Holthuijsen, L., Smith, J., 2014. Non-hydrostatic modeling of surf zone wave dynamics. Coastal Engineering, 83, 36-48.

Stelling, G., Zijlema, M., 2003. An accurate and efficient finite-difference algorithm for nonhydrostatic free-surface flow with application to wave propagation. International Journal for Numerical Methods in Fluids, 43(1), 1-23.

Suhayda, J.N., 1974. Journal of Geophysical Research Atmospheres 79(21):3065-3071, DOI: 10.1029/JC079i021p03065

Sutherland, J., O’Donoghue, T., 1998. Characteristics of wave reflection spectra. J. Waterw. Port Coastal Ocean Eng., 124(6), 303-311.

Taira, K., Nagata, Y., 1968. Experimental study of wave reflection by a sloping beach. Journal of Oceanographical Soc. Japan, 24(5), 242-252

Tonelli, M., Petti, M., 2012. Shock-capturing Boussinesq model for irregular wave propagation. Coastal Engineering, 610 8-19. 
Torres-Freyermuth, A., Mariño Tapia, I., Coronado, C., Salles, P., Medellín, G., PedrozoAcuña, A., Silva, R., Candela, J., Iglesias-Prieto, R., 2012. Wave-induced extreme water levels in the Puerto Morelos fringing reef lagoon, Nat. Hazards Earth Syst. Sci., 12 37653773.

Zijlema, M., Stelling, G.S., Smit, P.B., 2011. SWASH: an operational public domain code for simulating wave fields and rapidly varied flows in coastal waters, Coastal Engineering. 58 992-1012. 
Click here to access/download Electronic Supplementary Material OD_20180314.pdf 